\title{
Reaching Out to Those in Need: The Case for Community Health Science
}

\author{
Mark J. DeHaven, PhD, and Nora E. Gimpel, MD
}

The present health care delivery model in the United States does not work; it perpetuates unequal access to care, favors treatment over prevention, and contributes to persistent health disparities and lack of insurance. The vast majority of those who suffer from preventable diseases and health disparities, and who are at greatest risk of not having insurance, are minorities (Native Americans, Hispanics, and African Americans) and those of lower socioeconomic status. Because the nation's poor are most affected by built-in inequities in the health care system and because they have little political power, policy makers have been able to ignore their responsibility to this group.

Family medicine leaders have an opportunity to integrate community health science into their academic departments and throughout the specialty in a way that might improve health care for the underserved. The specialty could adapt existing structures to better educate and involve students, residents, and faculty in community health. Family medicine can also involve community practices and respond to community needs through practice based research networks and community based participatory research models. It may also be possible to coordinate the community activities of family medicine organizations to be more responsive to the health crisis of those in need. More emphasis on community health science is consistent with family medicine's roots in social reform, and its historical and philosophical commitment to the principle of uninhibited access to medical care for the underserved. (J Am Board Fam Med 2007;20:527-532.)

Everyone who believes that the current health care system in the United States is not working faces important and uncomfortable choices between recognizing and challenging the inequities in health outcomes or ignoring them; perceiving and defining the present system's contribution to iniquity or denying it; and advocating for those suffering from persistent health disparities or turning away from them.

Family medicine is the natural specialty for leading efforts to improve care for the underserved because it approaches illness from the biopsychosocial perspective, emphasizing the importance of biological, psychological, and social determinants

This article was externally peer reviewed.

Submitted 25 August 2006; revised 19 March 2007; accepted 26 March 2007.

From the Department of Family and Community Medicine, UT Southwestern Medical Center, Dallas, TX.

Funding: none.

Conflict of interest: none declared.

Corresponding author: Mark J. DeHaven, $\mathrm{PhD}$, Department of Family and Community Medicine, UT Southwestern Medical Center, 6263 Harry Hines Boulevard, Dallas, TX 75390-9067 (E-mail: mark.dehaven@UTSouthwestern.edu). of health. Family medicine has its roots in social reform and has sought leaders concerned with addressing the public's medical needs. ${ }^{1}$ The specialty has a historical and philosophical commitment to the principle of uninhibited access to medical care for everyone, especially the underserved.

The present health care delivery system in the United States is characterized by persistent disparities in health outcomes, growing numbers of uninsured people, and the decline of safety net providers. $^{2}$ As a consequence, increasing numbers of predominantly minority and low-income people suffer disproportionately from frequently preventable medical conditions. Here we present our thoughts about preventable disease, health and health disparities, and the opportunity for family medicine to take more of a leadership role in addressing these needs through more active community engagement.

\section{When Is Suffering Not Normal?}

For many years we have observed-as a community medicine researcher and division chief in departments of family medicine in 2 major cities (M.J.D.) 


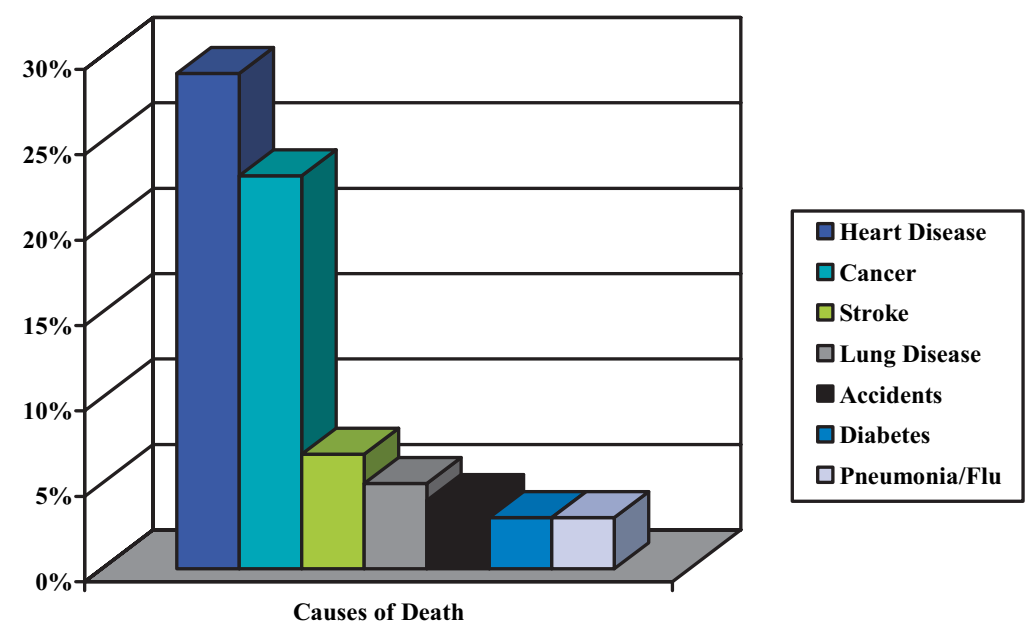

Figure 1. Factual causes of death, "facts of life."

and as an attending physician in underserved communities (N.E.G.) - that economically vulnerable individuals and families (usually minorities) are victims of a form of health-related suffering euphemistically called "health disparities." Generally speaking, disparities refer to the differences that exist in disease prevalence, health outcomes, or access to health care based on population characteristics. Common disparities include Native Americans being twice as likely as whites to develop diabetes; Hispanics being twice as likely to die from diabetes; and African Americans having a $40 \%$ higher death rate from heart disease. ${ }^{3}$

It is difficult to understand how substantial disparities persist in a country that devotes $15.3 \%$ of its gross domestic product to health care $(\$ 1.7$ trillion), or $\$ 6,040$ per capita. ${ }^{4}$ One explanation is implicit and explicit rationing. Implicit rationing controls access to care based on income, whereas explicit rationing is based on other standards such as lottery or disease severity. In the United States, health care is rationed implicitly. On one end of the continuum are those with access to the best health care in the world (our colleague calls this the "Neiman Marcus" plan because it is very exquisite by any standard and vastly overpriced). On the other end are the more than 45.5 million adults between the ages of 18 and 64 years of age $e^{5}$ with no health insurance, who are disproportionately ethnic minorities: more than a third of Hispanics and more than $25 \%$ of Native Americans, $21 \%$ of African Americans, and 18\% of Asian Americans are uninsured, compared with approximately $13 \%$ of whites. ${ }^{6}$
The uninsured are less likely to receive preventive care, 3 times more likely to postpone seeking costly care, 4 times more likely to not get needed care, 3 to 4 times more likely to report problems in receiving such care, more likely to be diagnosed with late-stage cancer, and more likely to be hospitalized for preventable conditions. ${ }^{7}$ In a theoretical sense, health-related suffering and differences in health status seem to be a normal part of the human experience. However, when identifiable groups are systematically denied routine access to medical care and are subjected to increased risk of disease and diminished quality of life, the circumstance is at best not normal and at worst immoral.

\section{What Can Be Done?}

Two alternative ways for understanding disease and causality are in terms of the life of the human organism and the type of life a human organism is living. For descriptive purposes these can be called the facts of life and truth about living perspectives, respectively. The former explains morbidity, mortality, and health outcomes in terms of individual organs or organ systems; treatment is directed primarily at resolving existing disease symptoms and mortality is a function of organism-specific mechanisms $^{8}$ (Figure 1).

The truth about living perspective recognizes that lifestyle and other social variables explain when, why, and how a person's life will probably end. Ergo, although heart disease may appear on the death certificate, often smoking, poor nutrition, and lack of exercise actually cause premature death ${ }^{9}$ 


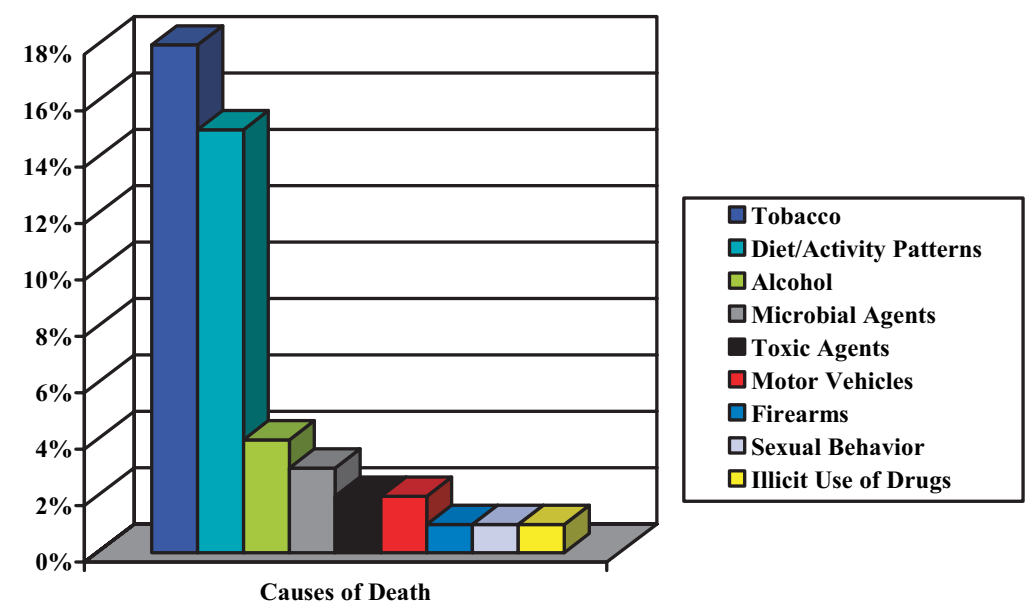

Figure 2. Actual causes of death, "truth about living."

(Figure 2). This perspective recognizes that premature death is affected by lifestyle and behavior $(50 \%)$, as well as environmental $(20 \%)$, genetic $(20 \%)$, and access to care (10\%) variables ${ }^{10}$ (Figure $3)$. The perspective recognizes that these disease determinants are also influenced by policies and interventions. ${ }^{11}$ Accordingly, reducing disease prevalence requires implementing broad-based prevention strategies addressing biological, lifestyle/behavioral, and societal variables. ${ }^{12}$ This approach is especially significant because most primary care is directed more toward treatment at the expense of preventive care. ${ }^{13}$

\section{Current Health Care Delivery}

There is no incentive for those with insurance to modify their unhealthy behaviors in a way that might reduce chronic disease prevalence and health care costs, as long as they can receive treatment for

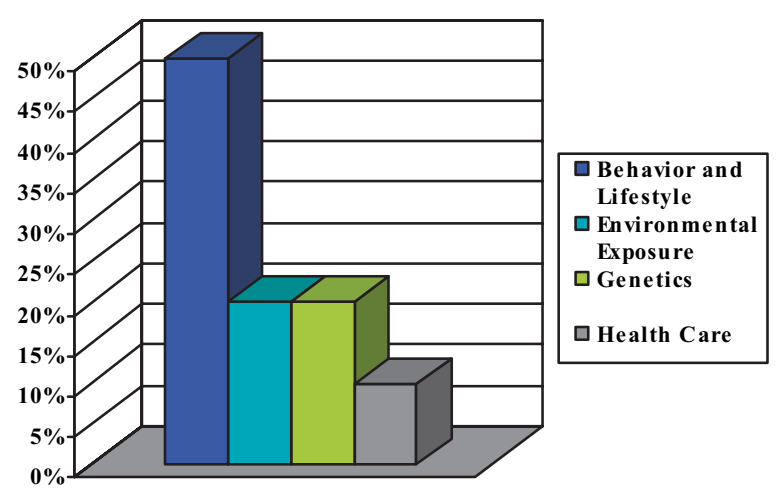

Figure 3. Determinants of health. preventable conditions related to lifestyle factors such as smoking. Simultaneously, as treatment becomes more expensive, increasing health care costs will keep expensive health insurance, preventive screening, patient education, and disease treatment beyond reach of the uninsured. Thus, the uninsured will continue to experience more frequent emergency department use and hospital admissions, and a 3-fold increased likelihood of dying in the hospital. ${ }^{14}$

\section{Promoting Health in Communities}

Health is a comprehensive concept referring to a state of physical, mental, and social well-being ${ }^{15}$ that helps people cope with and overcome disease and other disruptions to routine living. An effective health system can promote equity and quality by (1) addressing community-based health promotion and primary prevention beyond the confines of the clinical setting, (2) improving primary care medicine's ability to address primary and secondary prevention, and (3) reducing the need for expensive hospital-based tertiary services. Of course, the obstacles to this type of approach are formidable, including present reimbursement mechanisms favoring treatment over prevention and the tertiary care orientation of most medical centers. ${ }^{16}$ However, through innovative thinking and bold leadership it may be possible to do the right thing for those in need while introducing a more rational approach based on prevention into the US health care system. 


\section{Integrating Primary, Secondary, and Tertiary Prevention}

Innovative models for integrating primary, secondary, and tertiary prevention abound when health care resources are limited. Health providers in the growing realm of free and volunteer clinic care in the United States ${ }^{17}$ are fast realizing that care delivery must focus less on treatment and more on prevention. ${ }^{18}$ Innovative systems of care such as Project Access in Dallas, Texas, have been developed for providing access to care across the full range of preventive services. ${ }^{19}$ Similarly, financially strapped countries have been forced to reduce demand for expensive medical care. The Programa de Desarrollo Humano Oportunidades is a comprehensive program for addressing the full range of health and social needs among Mexico's impoverished population that requires children's enrollment in school and adult participation in community-based health promotion and disease prevention. ${ }^{20}$ Clinics providing medical care have an incentive to participate with the community to improve health outcomes because the care providers deliver is expected to be $70 \%$ prevention and $30 \%$ treatment. By working with the community to promote health, providers limit spending on more expensive disease treatment.

\section{Community Health Science Must Be Part of the Solution}

Although community medicine exists at the intersection of clinical medicine, public health, and social science, ${ }^{21}$ the possible role of family medicine in such a system has never been fully described or operationally defined. Clinical medicine concentrates on individuals (micro-level) and seeks to diagnose, treat, and prevent disease by maximizing patients' health and functional capacity. Public bealth concentrates on populations (macro-level) and seeks to maintain health through collective action; social science applies the scientific method to the understanding of human interactions and relationships. By linking clinical care and epidemiology with community partners and organizations it is possible to envision a scientific approach to community health (community health science) in which health is a social outcome resulting from systematically combining clinical science, collective responsibility, and informed social action. ${ }^{21}$

\section{Family Medicine Leadership Academic Departments}

Community health science can play a significant role in our academic institutions and departments of family medicine. More than 3 decades ago, Kurt Deutschle envisioned a medical school where the basic science faculty conduct research to improve understanding disease, clinical researchers translate the knowledge into practice, and the community medicine faculty integrate this knowledge into the human population and identify new health problems. ${ }^{22}$ Family medicine's multiple missions could easily accommodate the knowledge, attitudes, and skills needed for students, residents, and faculty to manage family health through effective community-integrated health promotion and disease prevention strategies.

Innovative programs are available for introducing medical students to family medicine and promoting community engagement and reaching vulnerable communities..$^{23}$ From other specialties it is possible to learn how to replace the sometimes nominal residency training experiences that provide limited experience addressing community concerns with those emphasizing how to actually improve community conditions that place people's health at risk. ${ }^{24}$ Family medicine faculty can play a significant role in translating basic science research into clinical and community applications as participants in the National Institutes of Health's new emphasis on clinical and translational sciences emphasizing the research continuum from bench to bedside to curbside. ${ }^{25}$ Medical institutions are seeking leadership in how to engage communities for their Clinical and Translational Sciences Awards, and family medicine has the experience and ability to provide the leadership.

\section{Practice-based Research and Collaboration}

A community health science approach encourages us to think boldly about how to address the public's needs and promote healthy lifestyles through collaboration among basic scientists, clinical investigators, community-based practitioners, and community organizations such as schools, businesses, nonprofit organizations, government, and faithbased organizations. Collaborative approaches could unite family medicine practice and educational and research missions in a way that advances the specialty and improves the health of the com- 
munity. Practice-based research networks could actively recruit and engage community representatives among the members of their governing boards and, by using more community-based participatory research approaches, begin to systematically address the community's health promotion and disease prevention needs. ${ }^{26}$

\section{Advocacy and Coordinating Approaches}

Numerous family medicine organizations, such as The Robert Graham Center, have devoted considerable resources and attention to promoting access to primary care and health equity. Others, such as the Coastal Research Group's National Project on the Community Benefits of Family Medicine Residency Programs, have focused attention on issues such as the contribution of family medicine training programs to the communities in which they are located. Activities in these and other areas related to community health and engagement need to be better understood and more aggressively pursued throughout the entire specialty. The confluence of national imperatives related to reducing preventable chronic disease and health disparities, addressing the problems of the uninsured, improving approaches to health promotion and disease prevention, and the growing importance of community-engaged research through the National Institutes of Health provide an unprecedented opportunity for aggressive leadership on issues consistent with family medicine's history and philosophy. It may be possible to develop a focused community health agenda for the specialty, and the nation, through actions such as (1) vertically integrating teaching and research initiatives in community health for medical students, residents, fellows and faculty and (2) integrating the separate community health practice, advocacy, research, and teaching perspectives of the separate specialty organizations into a centralized data-gathering and -reporting authority. Developing a consensus plan among family medicine organizations for documenting community health needs and ways family medicine is currently addressing the needs, and defining the role of the specialty (and possibly others) in addressing the unmet needs would provide a bold and pragmatic new vision for the 21 st century.

\section{Statistical Compassion}

Greater collaboration between family medicine at all levels and public health and community organi- zations offers the hope of statistical compassion, or a more equitable distribution of disease burden free of sociodemographic distortions. ${ }^{21}$ Our communities need help in curbing increasing health disparities and chronic disease prevalence, and organized medicine needs leadership if it is to remain viable in the face of the chronic health needs of our society. The opportunity exists to honor family medicine's heritage while doing good for those in need by taking steps to reduce the significant but preventable suffering among countless people and families in communities throughout our society.

The authors would like to thank Cynthia Haq, MD, and Kurt Stange, MD, for their comments on earlier drafts of this essay; Jessica Scarf, MS, and Jen Creer for editorial assistance; and Larry James and Jim Walton, DO, for helping us better understand the need for community health science.

\section{References}

1. Stephens GG. Family medicine as counterculture. 1979. Fam Med 1998;30:629-36.

2. Institute of Medicine. America's health care safety net: intact but endangered. Washington, DC: $\mathrm{Na}-$ tional Academy Press; 2000.

3. Department of Health and Human Services. Healthy People 2010: understanding and improving health. 2nd ed. Washington, DC: US Government Printing Office; 2000.

4. Heffler S, Smith S, Keehan S, Borger C, Clemens CK, Truffer C. Trends: US health spending projections for 2004-2014. Health Aff (Millwood) 2005 Available from http://content.healthaffairs.org/ content/vol0/issue2005/images/data/hlthaff.w5.74/ DC1/Heffler05 Ex1.gif. Accessed 22 August 2006.

5. The Kaiser Commission on Medicaid and the uninsured. Health Insurance Coverage in America. 2004 data update (2005). Available from http://www. kff.org/uninsured/7415.cfm. Accessed 22 August 2006.

6. The Kaiser Commission on Medicaid and the Uninsured. The uninsured: a primer. Key facts about Americans without health insurance (2003). Available from http://www.kff.org/uninsured/4085.cfm. Accessed 11 August 2004.

7. The Kaiser Commission on Medicaid and the Uninsured. Access to care for the uninsured: an update (2003). Available from http://www.kff.org/ uninsured/4142.cfm. Accessed 24 August 2006.

8. Kochanek KD, Murphy SL, Anderson RN, Scott C. Deaths: final data for 2002. Nat Vital Stat Rep 2004; 53:1-116.

9. Mokdad AH, Marks JS, Stroup DF, Gerberding JL. Actual causes of death in the United States, 2000. JAMA 2004;291:1238-46; erratum JAMA 2005;293: 293-4, 298. 
10. Lee P, Paxman D. Reinventing public health. Annu Rev Public Health 1997;18:1-35.

11. US Department of Health and Human Services. Healthy People 2010. Available at www.healthypeople.gov. Accessed 24 November 2006.

12. Institute of Medicine Committee on Health and Behavior. Health and behavior: the interplay of biological, behavioral, and societal influences. Washington, DC: National Academy Press; 2001.

13. Stange KC, Flocke SA, Goodwin MA, et al. Direct observation of rates of preventive service delivery in community family practice. Prev Med 2000;31:16776.

14. Families USA Foundation. Getting less care: the uninsured with chronic health conditions (2001). Available from: http://www.familiesusa.org/assets/ pdfs/gettinglesscare387c.pdf. Accessed 11 August 2004.

15. World Health Organization. World Health Organization definition of health. Preamble to the Constitution of the World Health Organization as adopted by the International Health Conference, New York, 19-22 June 1946.

16. Gellert GA. US health care reform and the economy of prevention. Arch Fam Med 1993;2:563-7.

17. Ferrer RL. Within the system of No-System. JAMA 2001;286:2513.

18. Bibeau DL, Taylor ML, Rife JC, Howell KA. Reaching the poor with health promotion through community free clinics. Am J Health Promot. 1997; 12:87-9.

19. DeHaven MJ, Walton J, Edwards C, et al. Social return on investment: capturing and monetizing the positive externalities generated by increased access to health care in Project Access patients. Presented at the 131st Annual Meeting of the American Public Health Association, San Francisco, California, 15-19 November 2003.

20. Birn AE. Federalist flirtations: the politics and execution of health services decentralization for the uninsured population in Mexico, 1985-1995. J Public Health Policy 1999;20:81-108.

21. Silver AL, Rose DN. Kurt W Deuschle and community medicine: clinical care, statistical compassion, community empowerment. Mount Sinai J Med 1992;59:439-43.

22. Koplan JP, Thacker SB. Deuschle: the clinician in the community. Mt. Sinai J Med 1992;59:444-6.

23. DeHaven MJ, Chen LL. Teaching medical students research while reaching the underserved. Fam Med 2005;37:315-7.

24. Willis E, Frazer T, Kliegman RM. Value of a community pediatrics rotation for residents. J Pediatr 2006;148:287-8.

25. Ewigman B, Newton W, Davis A, Chen F, Michener L. The role of family medicine departments in NIH Clinical Translational Science Award applications. Presented at the Annual Meeting of the North American Primary Care Research Group, Tuscon, Arizona, 15-18 October 2006.

26. Macaulay AC, Nutting PA. Moving the frontier forward: incorporating community-based participatory research into practice-based research networks. Ann Fam Med 2006;4:4-7. 